unfortunately not quantitative. As stated explicitly in the title of Kety and Schmidt's first JCI paper, generating a quantifiable measure was a key achievement of their original efforts. The absence of quantification is one of the main reasons that BOLD fMRI has yet to make significant contributions to clinical neuroscience, such as reliably mapping neurologic or psychiatric illness. It is this potential clinical utility, one that emerged from Kety's lifelong interests, that motivates the current crop of fMRI investigators. The combination of innovation and rigor that characterized Kety and Schmidt's landmark papers serves as a model to us all.
Address correspondence to: Scott A. Small, Columbia University, College of Physicians and Surgeons, 630 West 168th Street, New York, New York 10032, USA. Phone: (212) 305-9194; Fax: (212)342-2849; E-mail: sas68@columbia.edu.

1. Roy, C.S., and Brown, J.G. 1879. The blood pressure and its variation in the arterioles, capillaries and smaller veins. J. Physiol. 2:323-359.

2. Gaskell, T.W.H. 1880. On the tonicity of the heart and blood vessels. J. Physiol. 3:38-75

3. Hill, L. 1896. The physiology and pathology of the cerebral circulation: an experimental research. J. \& A. Churchill. London, United Kingdom. 208 pp.

4. Roy, C.S., and Sherrington, C.S. 1890 . On the regulation of the blood supply of the brain. J. Physiol. 11:85-108.
5. Friedland, R.P., and Iadecola, C. 1991. Roy and Sherrington (1890): a centennial reexamination of "On the regulation of the blood-supply of the brain”. Neurology. 41:10-14.

6. Sokoloff, L. 2000. In memoriam: Seymour Kety, M.D. 1915-2000. J. Cereb. Blood Flow Metab. 20:1271-1275

7. Kety, S.S., and Schmidt, C.F. 1948. The nitrous oxide method for the quantitative determination of cerebral blood flow in man: theory, procedure and normal values. J. Clin. Invest. 27:476-483.

8. Kety, S.S., and Schmidt, C.F. 1948. The effects of altered arterial tensions of carbon dioxide and oxygen on cerebral blood flow and cerebral oxygen consumption of normal young men. J. Clin. Invest. 27:484-492.

9. Ogawa, S., Lee, T.M., Nayak, A.S., and Glynn, P. 1990. Oxygenation-sensitive contrast I magnetic resonance image of rodent brain at high magnetic fields. Magn. Reson. Med. 14:68-78.

\title{
The legacy of Homer W. Smith: mechanistic insights into renal physiology
}

\section{Gabriel Navar}

Department of Physiology and Hypertension and Renal Center of Excellence, Tulane University Health Sciences Center, New Orleans, Louisiana, USA.

\begin{abstract}
In 1945, Homer W. Smith published an article in the JCI that clearly demonstrated that para-aminohippuric acid is the most suitable agent for the evaluation of renal plasma flow in both humans and dogs; in addition, the paper provided detailed methodology that is still in use today. This paper is but one of many outstanding works performed by Smith and his colleagues that clearly established the clearance technique as a powerful noninvasive approach to gain mechanistic insights into intrarenal function.
\end{abstract}

In light of today's practices by many prestigious journals seeking the holy grail of impact factor, it is entirely possible that Homer W. Smith (Figure 1), legendary renal physiologist and prolific author of numerous publications in the Journal of Clinical Investigation during the 1930s and '40s, would have been given a polite but firm rejection of one of the most cited articles that has been published in the JCI (1). "Dear Dr. Smith," the letter would say, "the Editorial Board regrets to inform you that it feels that your paper would be more appropriate for a specialized journal of kidney research; in addition, it was felt that your paper is primarily descriptive in nature." In reality, this highly-cited paper $(2,407$ times as of this writing) by Smith and his associates is a meticulously docu-

Nonstandard abbreviations used: $\mathrm{PAH}$, para-aminohippuric acid.

Conflict of interest: The author has declared that no conflict of interest exists.

Citation for this article: J. Clin. Invest. 114:1048-1050 (2004). doi:10.1172/JCI200423150. mented - albeit descriptive - work evaluating the differences among a number of organic acids that are excreted by the kidney with very high efficiency because they undergo tubular secretion (1).

This paper is but one of a long string of studies by Smith's laboratory group during the 1930s and '40s. Smith and his associates were incredibly prolific and contributed greatly to the development of many important concepts in renal physiology, in particular those related to the use of the clearance technique to determine how specific substances are handled by the kidneys (2). His efforts to integrate knowledge in renal physiology are readily reflected in his monumental work, entitled The kidney: structure and function in bealth and disease, published in 1951 (2). His outstanding contributions to the world of renal physiology have been noted by many of his trainees and documented in the book published by Chasis and Goldring in 1965 (3). The book includes, in addition to several of his speeches and essays, talks given in honor of Smith. In the words of
S.E. Bradley at a dinner in 1962, "Homer Smith and the school Homer Smith has nurtured have been responsible for the major discoveries that link New York University and the kidney in men's minds the world over." Bradley also reflected on the insatiable curiosity of Smith in recounting when, as a young renal physiologist in Charlottesville, Virginia, Smith generated attention by following circus camels, pot in hand, so that he could collect their urine and try to understand how these animals could excrete such concentrated urine.

In his address before the National Academy of Sciences shortly after Smith's death in 1962, R.F. Pitts eloquently placed in perspective his extraordinary contributions. "Smith was the first to understand what renal clearance really meant and to appreciate what a powerful tool the clearance concept could be if properly justified and applied ... For over thirty years, he dominated his chosen field in a way that few, if any, have dominated other fields. His personal investigations, his broad and inclusive concepts, the methods of study of function which he developed and popularized, the texts that he wrote, and the many investigators and students of medicine whom he trained and influenced established him as the acknowledged master of all things renal."

A strong advocate of the importance of collaborations between preclinical and clinical departments, Smith was a driving 


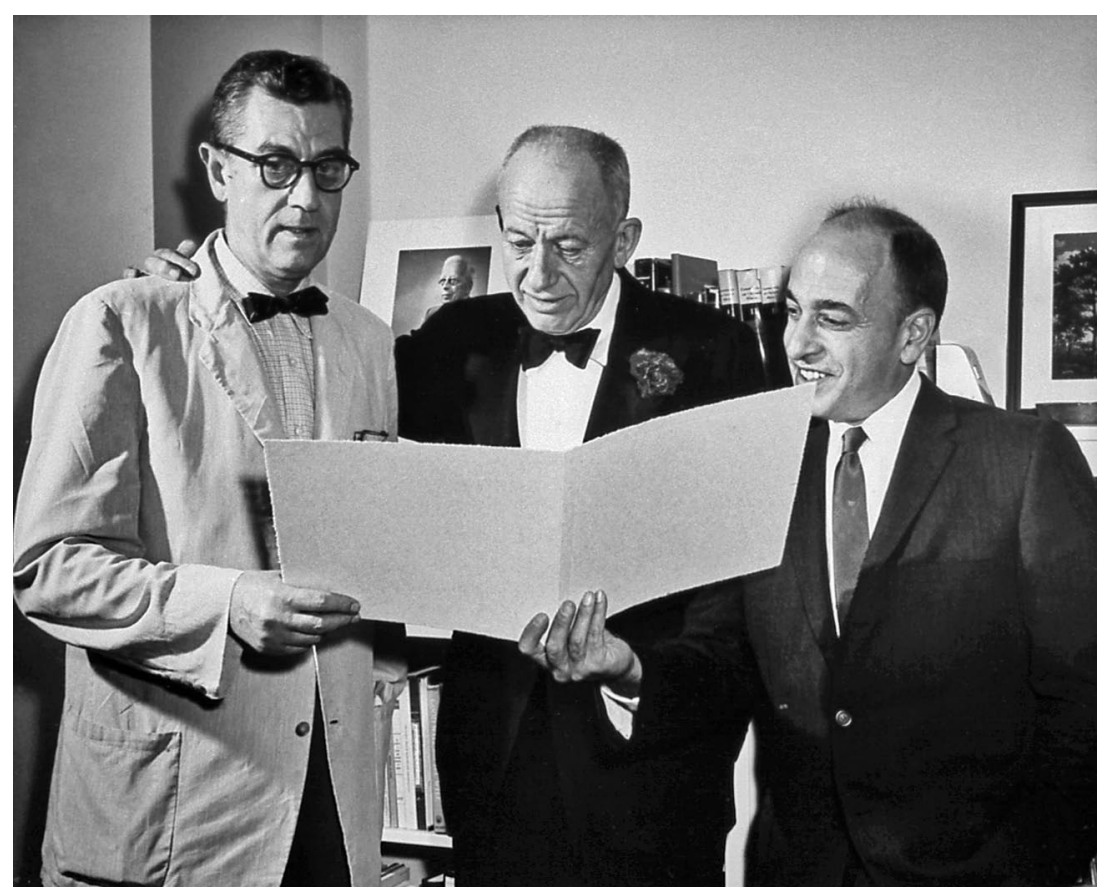

Figure 1

James A. Shannon, Robert Berliner, and Homer W. Smith (center) prior to Smith's lecture on April 26, 1960 (NIH, Bethesda, Maryland, USA). Image courtesy of the National Library of Medicine.

force in bringing together physiologists and clinical scientists. How much more timely could his example be as we again hear calls for greater interactions between basic and clinical scientists and make efforts to encourage more translational research? It seems appropriate to reconsider him as a role model for stimulating interdisciplinary collaborations and the mentorship of young physician-scientists. For, beyond personal scientific accomplishments, the legacy of investigators is best measured by the impact that they have had on the minds of those that trained with them. In this regard, Smith casts a huge shadow, having had many trainees and disciples, a partial list which is included in the book by Chasis and Goldring (3).

The JCI article serves as an excellent example of the efforts by Smith to bring a rigorous discipline to the science of clearance methodology and highlights the importance of meticulous work that allows definitive conclusions that can provide a cornerstone for future work. Without a doubt, the justification for performing the detailed analysis presented in this article was that the renal clearances of such agents were so high as to approach complete clearance in a single pass. Accordingly, clearances of such agents could be used to approximate renal plasma flow without the need for blood sampling from the renal vein to determine the extraction rate (4). However, it was important to establish which of the many hippuric acid derivatives was most efficiently excreted and to compare the hippuric acid clearances with that of diodrast, an agent that was also being used to measure renal plasma flow. An additional issue addressed by these experiments was the extent to which the organically bound iodine was responsible for the tubular secretion. As it turned out, the iodine didn't make any difference, and this aim of the study took a back seat to the rest of the findings.

Considering the fact that Smith's paper is indeed primarily descriptive, one can justifiably ask why it has been cited so extensively. The answer is that it provides a definitive statement supported by extensive documentation that paraaminohippuric acid (PAH) is the most suitable and convenient substance for the evaluation of "effective" renal plasma flow. After comparing clearances among 14 agents relative to the clearances of inulin and creatinine, the authors concluded that PAH was the most advantageous of the agents tested for the mea- surement of renal plasma flow because it had a clearance equal to that of diodrast but was much easier to measure, had very low endogenous activity, did not penetrate red blood cells, was nontoxic, and was bound less to plasma proteins than diodrast (1). In addition, it was concluded that PAH was also the agent of choice for the evaluation of "tubular excretory mass," which could be used as an index of functional tubular parenchyma (5). Thus, this paper established the foundation for the thousands of subsequent studies that used PAH to determine renal plasma flow in humans and experimental animals. In addition to the extensive clearance data provided, the detailed Methods section describes a simplified analysis of PAH based on the method originally described by Bratton and Marshall (6). The combination of a definitive statement touting the superiority of PAH over other agents and explicit instructions for performing the analysis served this paper and its authors very well indeed. It still remains an appropriate paper to reference when using PAH determinations for the estimation of renal plasma flow.

Renal physiologists have long appreciated that precise regulation of blood flow through the kidney is very important for the ability of the organ to properly perform its excretory function. By appropriate regulation of the vascular resistances of afferent and efferent arterioles, the dynamics in the glomerular and peritubular networks are continuously adjusted to maintain them in balance with the metabolically determined transport function of the tubules. The postglomerular microcirculation separates into two distinct pathways, perfusing the cortex and medulla, respectively. In each case, microcirculatory dynamics are regulated to provide the appropriate environment for the tubular network. Because many renal diseases are first manifested by a derangement in renal microcirculatory dynamics, it is not surprising that Smith was so interested in obtaining the most reliable estimate of the blood flow perfusing functional renal tissue.

In his studies of clearance, Smith used the term "effective" when referring to renal plasma flow based on PAH clearances. However, one can ask, what is so effective about "effective" renal plasma flow? To find the source of this term, it is necessary to go to other papers by Smith and his associates $(5,7)$. In the 1938 paper 
by this group (7), effective renal plasma flow was defined as "the flow of plasma to active excretory tissue." This investigation recognized that actual plasma flow was higher than the clearances of diodrast or hippuric acids and attributed the difference to flow of plasma through "inert" tissue. The concept was based on the premise that the PAH in the plasma flowing through the capillaries surrounding "active" tissues, presumably the proximal tubules, was extracted with $100 \%$ efficiency. It was presumed that substantial blood flow went to perirenal fat, fibrous capsule, the pelves, calyces, and other inert tissues, and that this flow was not cleared of PAH (4). Consequently, the PAH clearance was interpreted as measuring the plasma flow through functional renal parenchyma. Smith acknowledged, however, that the term "effective" was cumbersome (4). We now know that there is very little inert tissue in normal kidneys, and essentially all of the blood flows through the glomeruli and is then distributed into the postglomerular capillary networks (8). Thus, the most direct explanation is that it is unlikely that any substance undergoing tubular secretion can be extracted completely in a single pass, and the residual amount of PAH in renal venous blood was due to incomplete extractions. In his book published in 1969, Wesson simply described the term effective as signifying that the $\mathrm{PAH}$ clearance does not represent blood that, for one reason or another, is not cleared of the test substance (9).

As mentioned, most of the postglomerular blood flow traverses the peritubular capillaries of the cortex, but a small percentage (about 20\%) flows through the vasa recta and medullary vessels $(8,10)$. This separation of the postglomerular blood flow into two distinct networks gave rise to a different notion: that the effective renal plasma flow represented the blood flowing only to the renal cortex. Pitts suggested that what distinguishes PAH clearance from total renal plasma flow is that PAH in plasma flowing to the medullary capillaries does not undergo as much secretion (11). By then, it was clearly realized that blood flow to inert tissues was not a viable explanation for the unextracted PAH.
Nevertheless, proximal straight tubules can also secrete organic acids, so that at least some of the PAH in postglomerular blood flowing to medullary tissues is also secreted. Although it is probable that the $\mathrm{PAH}$ is not extracted from the medullary postglomerular capillaries with the same efficiency as from cortical postglomerular capillaries, it is not likely that the "effective" renal plasma flow quantitatively represents the blood flow through the cortex. In essence, $\mathrm{PAH}$ clearances approach the renal plasma flow and provide an estimate of about $85-90 \%$ of the true plasma flow. Although the intent to assign a special meaning to PAH clearance was commendable, the term "effective" in referring to renal plasma flow based on PAH clearance is meaningless and should be discontinued. Investigators should simply refer to their PAH clearance data as renal plasma flow or "estimated" renal plasma flow uncorrected for incomplete extraction. Of course, if a renal venous sample is taken, then the PAH clearance can be corrected by the extraction ratio to provide a measure of total renal plasma flow (11). This additional step may be particularly important in disease conditions in which PAH extraction progressively declines in association with damage to the renal parenchyma.

The importance of Smith's contributions remains paramount to this day. Beyond his preeminence as a renal physiologist, however, it seems clear that Smith was a great philosopher and intellectual, always making an effort to integrate concepts and translate them to their greater meanings. In the words of his former students and admirers, "In addition to being an outstanding scientist, Homer Smith was a great teacher, an explorer, a philosopher, a novelist, and above all, a perennial student" (3). In the preface to his monumental treatise (2), Smith touted the principles of Claude Bernard and Walter Cannon regarding the importance of preservation of the "milieu interieur" and the concept of homeostasis. He further extended these concepts to apply to the importance of kidney function by saying, "in the last analysis, composition of the plasma is determined not by what the body ingests but by what the kidneys retain and what they excrete." This concept still rings true today and continues to provide a powerful motivation for the many in science who profess to be renal physiologists.

\section{Acknowledgments}

Special thanks go to Ushma Savla and the editors of the JCI for assistance in the preparation of this commentary. The author also thanks Debbie Olavarrieta for preparation of the manuscript and to Hector LiceaVargas for calling attention to the book about Homer Smith by Chasis and Goldring. For more insights into Smith's legacy and contributions, readers are encouraged to consult the book (3).

Address correspondence to: L. Gabriel Navar, Tulane Health Sciences Center, Department of Physiology, SL39, New Orleans, Louisiana 70112, USA. Phone: (504) 988-5251; Fax: (504) 988-2675; E-mail: navar@tulane.edu.

1. Smith, H.W., Finkelstein, N., Aliminosa, L., Crawford, B., and Graber, M. 1945. The renal clearances of substituted hippuric acid derivatives and other aromatic acids in dog and man. J. Clin. Invest. 24:388-404.

2. Smith, H.W. 1951. The kidney: structure and function in health and disease. Oxford University Press. New York, New York, USA. 1,049 pp.

3. Chasis, H., and Goldring, W., editors. 1965. Homer William Smith, Sc. D.: his scientific \& literary achievements. New York University Press. New York, New York, USA. 282 pp.

4. Smith, H.W. 1956. Principles of renal physiology. Oxford University Press. New York, New York, USA. 237 pp.

5. Chasis, H., Redish, J., Goldring, W., Ranges, H.A. and Smith, H.W. 1945. The use of sodium p-aminohippurate for the functional evaluation of the human kidney. J. Clin. Invest. 18:583-588.

6. Bratton, A.C., and Marshall, E.K., Jr. 1939. A new coupling component for sulfanilamide determination. J. Biol. Chem. 128:537.

7. Chasis, H., Ranges, H.A., Goldring, W., and Smith, H.W. 1938. The control of renal blood flow and glomerular filtration in normal man. J. Clin. Invest. 17:683-697.

8. Navar, L.G., Evan, A.P., and Rosivall, L. 1983. Microcirculation of the kidneys. In The physiology and pharmacology of the microcirculation. N. Mortillaro, editor. Academic Press. New York, New York, USA. 397-488.

9. Wesson, L.G. 1969. Physiology of the human kidney. Grune \& Stratton Inc. New York, New York, USA. 712 pp.

10. Navar, L.G., et al. 1996. Paracrine regulation of the renal microcirculation [review]. Physiol. Rev. 76:425-536.

11. Pitts, R.F. 1974. Physiology of the kidney and body fluids. 3rd edition. Year Book Medical Publishers Inc. Chicago, Illinois, USA. 315 pp. 